\title{
Effect of Surface Modification of Hydrated Titanium Dioxide on Its Selectivity to Strontium
}

\author{
A. V. Voronina* and V. S. Semenishchev \\ Yeltsin Ural Federal University, ul. Mira 19, Yekaterinburg, 620002 Russia; *e-mail: a.voronina_v@mail.ru \\ Received January 23, 2012
}

\begin{abstract}
The effect exerted on the selectivity of hydrated $\mathrm{TiO}_{2}$ to $\mathrm{Sr}$ by surface modification of the sorbent involving immobilization of mixed nickel potassium ferrocyanide was studied. The $\mathrm{Sr}$ specificity of the resulting sorbent (denoted as T-55) is comparable with that of hydrated $\mathrm{TiO}_{2}: \log K_{\mathrm{d}}\left(K_{\mathrm{d}}\right.$ is $\mathrm{Sr}$ distribution coefficient, $\left.\mathrm{ml} \mathrm{g}^{-1}\right)$ is $2.7 \pm 0.2$ in sorption from tap water with $\mathrm{pH} 7.8 \pm 0.2,2.7 \pm 0.5$ in sorption from $\mathrm{CaCl}_{2}$ solutions with $\mathrm{pH} 5.6 \pm 0.2$, and from $2.5 \pm 0.8$ to $1.7 \pm 0.4$ in sorption from $\mathrm{CaCl}_{2}$ solutions with $\mathrm{pH} 7.0 \pm 0.2$. The modification makes the resulting T-55 sorbent selective to $\mathrm{Sr}$ in the presence of $\mathrm{Ca}$ at $\mathrm{pH} 5-6$.
\end{abstract}

Keywords: hydrated titanium dioxide, nickel potassium ferrocyanide, strontium, sorption

DOI: $10.1134 / \mathrm{S} 1066362213010189$

Surface modification can be considered as a way to alter the specificity and selectivity of inorganic sorbents. Chemical modification of the surface allows synthesis of materials whose physical properties are determined by the support material, and chemical properties, by the nature of both the support and the compound immobilized on the surface. The resulting materials can acquire new properties, characteristic neither of the support nor of the compound being immobilized. Understanding of the relationships of chemical modification allows the material surface properties to be controlled depending on the practical demand.

A promising direction in synthesis of new sorption materials for preconcentration and immobilization of radionuclides is preparation of sorbents via surface modification of sorption-active supports having developed surface. The procedure includes heat treatment of supporting sorbents, leading to changes in the pore space, with the subsequent formation of stable nanosized compounds on the surface and in the pore space. By so doing, it is possible to prepare highly specific, polyfunctional, and complex sorbents. For example, ferrocyanide sorbents prepared by surface modification of hydrated $\mathrm{TiO}_{2}$ can be used for joint recovery of long-lived $\beta$-emitters such as ${ }^{137} \mathrm{Cs}$ and ${ }^{90} \mathrm{Sr}$ with the aim of their subsequent environmentally safe longterm storage or disposal [1].

Study of the effect exerted by chemical modification on the specificity and selectivity of support mate- rials to radionuclides and their chemical analogs is of scientific and practical interest.

Chemical modification of the surface of hydrated $\mathrm{TiO}_{2}$ (T-5 grade), which initially had no specificity to $\mathrm{Cs}$, by immobilization of mixed nickel potassium ferrocyanide makes the resulting material (denoted as $\mathrm{T}-55)$ Cs-specific. The procedure for preparing T-55 sorbent is described in [2]. In sorbent preparation, the internal part of the support matrix remains unmodified; therefore, the Sr-specific sorption sites are preserved. In this study we examined how surface modification of hydrated $\mathrm{TiO}_{2}$ by immobilization of mixed nickel potassium ferrocyanide affects its selectivity to $\mathrm{Sr}$.

\section{EXPERIMENTAL}

The performance of T-5 and T-55 sorbents in sorption of Sr from tap water was studied in batch experiments. The content of hardness salts, alkali metals, and anions in tap water corresponded to SanPiN (Sanitary Rules and Regulations) 2.1.4.1074-01. Namely, the

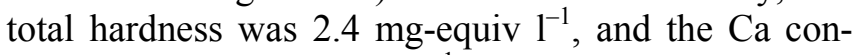
centration was $30 \pm 5 \mathrm{mg}^{-1}$. Water was preliminarily settled and filtered to remove iron hydroxide. The required $\mathrm{Sr}$ concentration in water was set by adding a solution of stable Sr; then, the sample was spiked with ${ }^{90} \mathrm{Sr}$. The sample volume was $V=50 \mathrm{ml}$, the sorbent weight was $20 \mathrm{mg}$, and $\mathrm{pH}$ of the initial solution was $7.8 \pm 0.2$. We obtained sorption isotherms for the phase contact times of 1 and 2 weeks. 
Experiments on the influence of $\mathrm{pH}$ on sorption were performed with tap water spiked with ${ }^{90} \mathrm{Sr}$. The $\mathrm{Sr}$ concentration was $1 \mathrm{mg} \mathrm{l}^{-1}$, with $\mathrm{V} / \mathrm{m}=50 \mathrm{ml} / 20 \mathrm{mg}$. The required $\mathrm{pH}$ was adjusted by adding $\mathrm{HCl}$ or $\mathrm{NaOH}$ solution.

The Sr selectivity of the sorbents was studied in the presence of calcium, which is the most naturally abundant analog of $\mathrm{Sr}^{2+}$. In our experiments we used $\mathrm{CaCl}_{2}$ solutions containing $0.05-110 \mathrm{~g} \mathrm{l}^{-1} \mathrm{Ca}$ and $1 \mathrm{mg} \mathrm{l}^{-1}$ stable $\mathrm{Sr}$ and spiked with ${ }^{90} \mathrm{Sr}$.

The Ca content of the solution was determined by complexometric titration with Murexide as indicator [3]. Radiometric measurements were performed with a UMF-2000 low-background radiometer with a semiconductor detector.

\section{RESULTS AND DISCUSSION}

Figure 1 shows the isotherms of $\mathrm{Sr}$ sorption from tap water at $\mathrm{pH} 7.8 \pm 0.2$. As can be seen, 1 week is sufficient to attain the sorption equilibrium in the system. The Henry law is observed throughout the examined interval of $\mathrm{Sr}$ concentrations $\left(10^{-5}-100 \mathrm{mg} \mathrm{1}^{-1}\right)$. The sorbent saturation was not attained, and therefore their static exchange capacity was not determined. We estimated the maximal content of $\mathrm{Sr}$ in the sorbent phase $\left(C_{\mathrm{s}}\right)$ at the $\mathrm{Sr}$ concentration in solution of $100 \mathrm{mg}^{-1}$. The equilibrium values of $\log K_{\mathrm{d}}\left(K_{\mathrm{d}}\right.$ is the Sr distribution coefficient, $\left.\mathrm{ml} \mathrm{g}^{-1}\right)$ and $C_{\mathrm{s}}\left(\mathrm{mg} \mathrm{g}^{-1}\right)$, calculated from the sorption isotherms, were as follows: for T-5, $2.8 \pm 0.2$ and 26; for T-55, $2.7 \pm 0.2$ and 34, respectively. Apparently, within the determination uncertainty, the $\log K_{\mathrm{d}}$ values for the initial hydrated $\mathrm{TiO}_{2}$ sample (T-5) and for the surface-modified sample (T-55) coincide; the maximal content of $\mathrm{Sr}$ in the sorbent phase at a $\mathrm{Sr}$ concentration in solution of $100 \mathrm{mg}^{-1}$ coincides also.

Figure 2 shows the $\mathrm{pH}$ dependence of the degree of Sr sorption by the initial T- 5 sorbent and by the modified sample (T-55). The $\mathrm{Sr}$ sorption is minimal at $\mathrm{pH} 3-4$ owing to competition of hydrogen ions. With a decrease in acidity, the degree of recovery of $\mathrm{Sr}$ sharply increases: for $\mathrm{T}-5$, in the interval $\mathrm{pH} 5-7$, and for $\mathrm{T}-55$, in the interval $\mathrm{pH}$ 6-8. Both sorbents show the highest $\mathrm{Sr}$ specificity in weakly alkaline and alkaline solutions. The maximum attainable $\mathrm{Sr}$ distribution coefficients with T-5 and T-55 sorbemts, calculated from the $S-\mathrm{pH}$ dependence, are $1.5 \times 10^{4}$ and $1.6 \times$ $10^{4} \mathrm{ml} \mathrm{g}^{-1}$, respectively.

In hydrated titanium dioxide (HTD), there are three
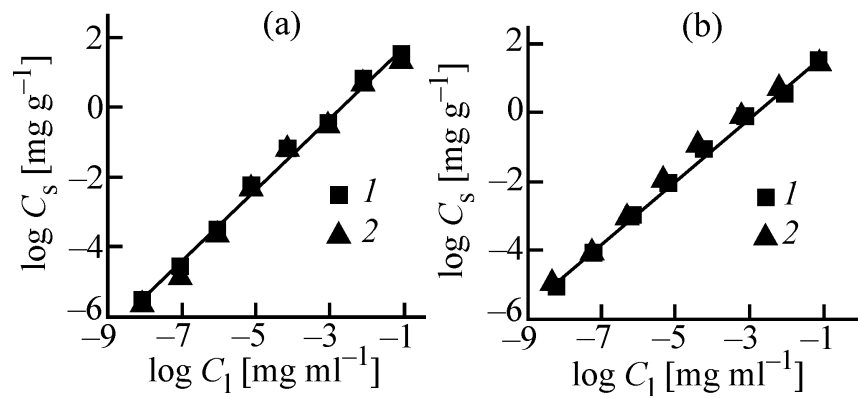

Fig. 1. Isotherms of $\mathrm{Sr}$ sorption by (a) $\mathrm{T}-5$ and (b) $\mathrm{T}-55$ sorbents from tap water at $\mathrm{pH} 7.8 \pm 0.2$. Phase contact time, weeks: (1) 1 and (2) 2.

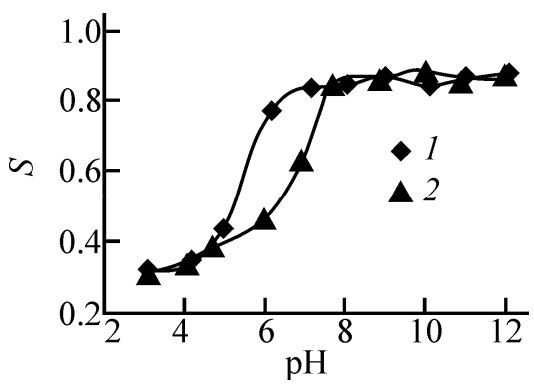

Fig. 2. pH dependence of the degree of Sr sorption $S$ by (1) T-5 and (2) T-55 sorbents.

types of sorption sites. With respect to the ionexchange activity and hence to the relative acidity, the oxygen-hydrogen groups can be ranked in the following order [4]:

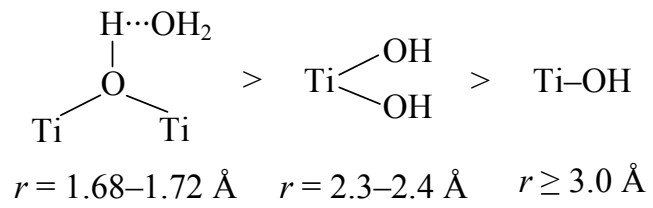

The $\mathrm{p} K$ values for HTD samples calcined at 150 $400^{\circ} \mathrm{C}$ are as follows [5]: $\mathrm{p} K_{1}=6.0-6.7, \mathrm{p} K_{2}=7.3-$ 8.2 , and $\mathrm{p} K_{3}=10.0-10.5$. Denisova [4] gives for hydrated $\mathrm{TiO}_{2} \mathrm{p} K_{1}=4.8 \pm 0.8$.

The interaction of $\mathrm{Sr}$ with the sorbent can be described by the reaction equation

$$
\left(\begin{array}{rl}
\equiv \mathrm{Ti}-\mathrm{O}-\mathrm{H} \\
\equiv \mathrm{Ti}-\mathrm{O}-\mathrm{H}
\end{array}\right)+2 \mathrm{H}_{2} \mathrm{O}+\mathrm{Sr}^{2+} \rightleftarrows \begin{aligned}
& \equiv \mathrm{Ti}-\mathrm{O} \backslash \\
& \equiv \mathrm{Ti}-\mathrm{O}
\end{aligned}>\mathrm{Sr}+2 \mathrm{H}_{3} \mathrm{O}^{+}
$$

Our results show that the Sr-specific sorption sites are preserved after surface modification of hydrated $\mathrm{TiO}_{2}$ with mixed nickel potassium ferrocyanide. The difference in the $S-\mathrm{pH}$ curves also suggests that, in modification of T-5 sorbent, the amount of acid groups 
Sorption of $\mathrm{Sr}$ and Ca by T-5 and T-55 sorbents from $\mathrm{CaCl}_{2}$ solutions

\begin{tabular}{c|c|c|c|c|c}
\hline \multirow{2}{*}{$\mathrm{pH}$} & \multirow{2}{*}{$\begin{array}{c}\text { Ca }] \text { in solution, } \\
\mathrm{g}^{-1}\end{array}$} & \multicolumn{2}{|c|}{$\mathrm{T}-5$} & \multicolumn{2}{c}{$\mathrm{T}-55$} \\
\cline { 3 - 6 } & & $\log K_{\mathrm{d}}(\mathrm{Sr})\left[\mathrm{ml} \mathrm{g}^{-1}\right]$ & $\log K_{\mathrm{d}}(\mathrm{Ca})\left[\mathrm{ml} \mathrm{g}^{-1}\right]$ & $\log K_{\mathrm{d}}(\mathrm{Sr})\left[\mathrm{ml} \mathrm{g}^{-1}\right]$ & $\log K_{\mathrm{d}}(\mathrm{Ca})\left[\mathrm{ml} \mathrm{g}^{-1}\right]$ \\
\hline $5.6 \pm 0.2$ & $0.05-110$ & No sorption & $2.0 \pm 0.4$ & $2.7 \pm 0.5$ & No sorption \\
$7.0 \pm 0.2$ & $0.05-2$ & $2.7 \pm 0.4$ & $2.0 \pm 0.6$ & $2.5 \pm 0.8$ & $2.3 \pm 0.6$ \\
$7.0 \pm 0.2$ & $2-110$ & $1.4 \pm 0.3$ (minimum) & $2.0 \pm 0.6$ & $1.7 \pm 0.4$ (minimum) & $2.3 \pm 0.6$ \\
\hline
\end{tabular}

dissociating at $\mathrm{pH} 5-6\left(\mathrm{H}_{3} \mathrm{O}^{+}\right.$ions $)$decreases.

We studied the selectivity of Sr sorption by T-5 and T-55 sorbents from $\mathrm{CaCl}_{2}$ solutions of various concentrations. To reveal the effect of the surface modification on the selectivity of the Sr sorption, we performed a series of experiments at $\mathrm{pH}$ set in the intervals 5-6 and 7-8, corresponding to $\mathrm{p} K_{1}$ and $\mathrm{p} K_{2}$ of the sorption groups of hydrated $\mathrm{TiO}_{2}$. Figure 3 shows how the Sr distribution coefficients in sorption by T-5 and $\mathrm{T}-55$ sorbents depend on the $\mathrm{Ca}$ activity in the
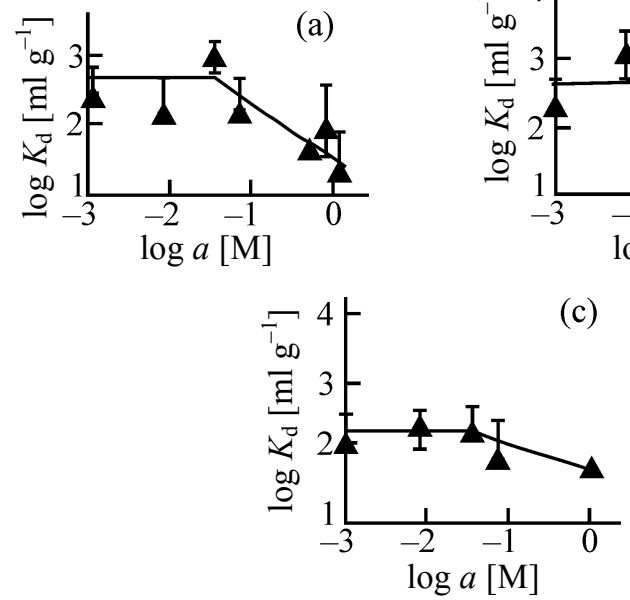

Fig. 3. Sr distribution coefficient as a function of $\mathrm{Ca}$ activity in solution. (a) T-5, pH $7.0 \pm 0.2$; (b) T-55, pH $5.6 \pm$ 0.2 ; and (c) T-55, $\mathrm{pH} 7.0 \pm 0.2$.
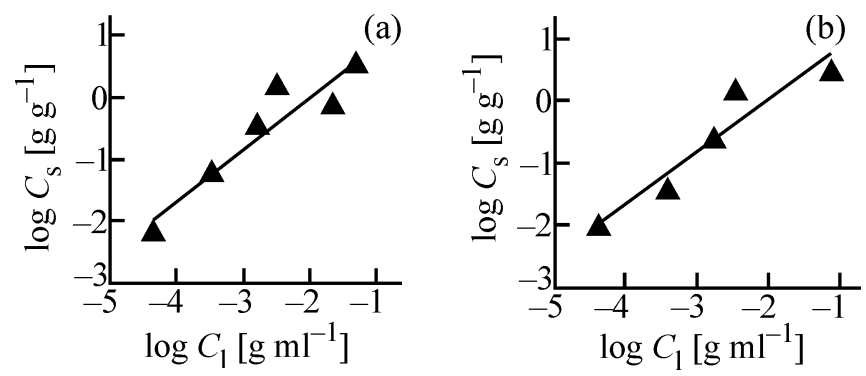

Fig. 4. Isotherms of Ca sorption by (a) T-5 and (b) T-55 sorbents at $\mathrm{pH} 7.0 \pm 0.2$. solution at $\mathrm{pH} 5.6 \pm 0.2$ and $7.0 \pm 0.2$, and Fig. 4 shows the isotherms of $\mathrm{Ca}$ sorption by T-5 and T-55 sorbents at $\mathrm{pH} 7.0 \pm 0.2$. The results of mathematical processing of the curves are given in the table.

As seen from the table, hydrated $\mathrm{TiO}_{2}$ of $\mathrm{T}-5$ grade in the examined $\mathrm{pH}$ intervals, $\mathrm{pH} 5.6 \pm 0.2$ and $7.0 \pm$ 0.2 , sorbs $\mathrm{Ca}$ with the distribution coefficients coinciding within the uncertainty. Strontium is not recovered by this sorbent at $\mathrm{pH} 5.6 \pm 0.2$. Presumably, the sorption of $\mathrm{Sr}$ is suppressed by the sorption of $\mathrm{Ca}$ present in higher concentration. At $\mathrm{pH} 7.0 \pm 0.2$, the sorption of $\mathrm{Sr}$ by $\mathrm{T}-5$ sorbent is unselective. The relationships are reproduced throughout the series of experiments at pH 5-6 and 7-8.

From aqueous solutions with $\mathrm{pH} 5-6, \mathrm{~T}-55$ sorbent sorbs $\mathrm{Sr}$ selectively: $\mathrm{Ca}$ is not recovered, and the $\mathrm{Sr}$ distribution coefficient is independent of the $\mathrm{Ca}$ concentration in the solution. The primary ion-exchange sites on hydrated $\mathrm{TiO}_{2}$ are $\mathrm{H}_{3} \mathrm{O}^{+}$ions [4]. As a result of modification with mixed nickel potassium ferrocyanide, the surface sorption groups of hydrated $\mathrm{TiO}_{2}$, dissociating at $\mathrm{pH} 5-6$, transform into groups that are selective to Cs but do not take up Sr. Because the modification occurs on the surface, it does not involve groups located inside sorbent granules. In this case, at $\mathrm{pH} 5-6, \mathrm{Sr}$ is probably sorbed only by the groups located inside a sorbent granule. Presumably, the selectivity of the $\mathrm{Sr}$ sorption in this $\mathrm{pH}$ range is determined by formation of the phase of mixed potassium nickel ferrocyanide on the surface of titanium hydroxide, preventing penetration of $\mathrm{Ca}$ into the sorbent granule, as hydrated $\mathrm{Ca}$ ion has larger size than hydrated $\mathrm{Sr}$ cation.

At $\mathrm{pH} 7-8$, sorption of $\mathrm{Sr}$ by T-55 sorbent is unselective. Calcium at $\mathrm{pH} 7.0 \pm 0.2$ is sorbed with $\log K_{\mathrm{d}}\left[\mathrm{ml} \mathrm{g}^{-1}\right]=2.3 \pm 0.6$, which coincides within uncertainty limits with the value obtained for T-5. At a $\mathrm{Ca}$ concentration of up to $2 \mathrm{~g} \mathrm{l}^{-1}$, the $\mathrm{Sr}$ sorption is independent of the $\mathrm{Ca}$ concentration in the solution, and at higher concentration $\mathrm{Ca}$ exerts a competing effect on Sr sorption. 
Thus, when the surface of hydrated $\mathrm{TiO}_{2}$ is modified by immobilization of mixed nickel potassium ferrocyanide, the sorbent preserves the Sr specificity comparable with that of hydrated $\mathrm{TiO}_{2}$ and, at the same time, becomes selective to $\mathrm{Sr}$ in the presence of $\mathrm{Ca}$ at $\mathrm{pH}$ 5-6.

\section{ACKNOWLEDGMENTS}

The study was supported by the Ministry of Education and Science of the Russian Federation (agreement no. 14.A18.21.0313).

\section{REFERENCES}

1. Voronina, A.V., Semenishchev, V.S., and Betenekov, N.D., Vopr. Radiats. Bezopasn., 2010, no. 3, pp. 54-61.

2. Voronina, A.V., Semenishchev, V.S., Nogovitsyna, E.V., and Betenekov, N.D., Radiokhimiya, 2012, vol. 54, no. 1, pp. 66-70.

3. Schwarzenbach, G. and Flaschka, H., Die komplexometrische Titration, Stuttgart: Enke, 1965.

4. Denisova, T.A., Doctoral (Chem.) Dissertation, Yekaterinburg: Inst. of Solid State Chemistry, Ural Branch, Russian Acad. Sci., 2009.

5. Sharygin, L.M., Malykh, T.G., Dorofeev, Yu.A., and Tret'yakov, S.Ya., Adsorbts. Adsorb. (Kiev), 1983, no. 11 , pp. 44-48. 